\title{
Factors Associated with Mortality in Geriatric Patients Presenting to the Emergency Department After Falls
}

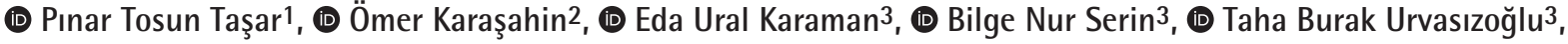 \\ (D) Sultan Tuna Akgöl Gür ${ }^{4}$, (D) Can Sevinç5 \\ ${ }^{1}$ Atatürk University Hospital, Clinic of Internal Medicine, Division of Geriatrics, Erzurum, Turkey \\ 2Erzurum Regional Training and Research Hospital, Clinic of Infectious Diseases, Erzurum, Turkey \\ ${ }^{3}$ Atatürk University Hospital, Clinic of Internal Medicine, Erzurum, Turkey \\ ${ }^{4}$ Atatürk University Hospital, Clinic of Department of Emergency Medicine, Erzurum, Turkey \\ ${ }^{5}$ Atatürk University Hospital, Clinic of Internal Medicine, Division of Nephrology, Erzurum, Turkey
}

\begin{abstract}
Objective: Few studies have investigated the impact of falls on mortality in older patients presenting to the emergency departments in our country. Thus, this study aimed to investigate the prognostic factors in geriatric patients with falls and identify the variables associated with repeated falls and mortality in the first 2 months after the fall.
\end{abstract}

Materials and Methods: The study included patients over 65 years of age who presented to the emergency department of our university due to falls between January and December 2019.

Results: A total of 170 patients were included in this study, with a mean age of $77.98 \pm 8.23$ years (median 78 years, range $65-99$ years), and 87 (51.2\%) were male. Albumin level of $<3.53 \mathrm{mg} / \mathrm{dL}$ was associated with an 8.066-fold higher risk of post-fall mortality [95\% confidence interval (Cl) 1.585-41.062, $p=0.012]$, whereas hemoglobin level of $<11.55 \mathrm{~g} / \mathrm{dL}$ was associated with a 5.488-fold higher risk $(95 \% \mathrm{Cl} 1.078-27.931, \mathrm{p}=0.040)$.

Conclusion: Among older adults who presented to the emergency department after falls, those with anemia and hypoalbuminemia at the time of admission had higher mortality. These two conditions were found to be independent risk factors for mortality. Thus, priority triage is recommended for these patients.

Keywords: Aging, older adults, falls, geriatrics, mortality

\section{Introduction}

Falls are a common geriatric syndrome in the older population. Studies have shown that about 1 in 3 older adults fall at least once every year and that of those who fall, about half fall more than once. Falls can result in serious injury and even death (1). This has been supported by findings from recent studies (2). Although the causes of falls are known to be multifactorial, the literature has shown that most falls are associated with physical fragility and cognitive dysfunction (3). Major risk factors for falls include sarcopenia, polypharmacy, orthostatic hypotension, arrhythmia, cognitive impairment, and cerebrovascular diseases. However, as with other geriatric syndromes, falls in older adults may be an indicator of underlying disease (4).
Approximately $40 \%$ of individuals aged 50 years or older present to the emergency department because of falls $(5,6)$. Most of these patients are sent home without being hospitalized (7) but they frequently return to the emergency department with another fall (8). Determining the factors associated with mortality in patients presenting with falls will facilitate triage and improve management of these patients with more efficient use of time.

In the literature, falls have been shown to be associated with hypoalbuminemia $(9)$, anemia $(10,11)$, and electrolyte imbalances such as hyponatremia and hypokalemia (12). In the present study, we aimed to investigate prognostic factors in geriatric patients with falls and identify variables associated with repeated falls and mortality in the first 2 months post fall.

Address for Correspondence: Pınar Tosun Taşar, Atatürk University Hospital, Clinic of Internal Medicine, Division of Geriatrics, Erzurum, Turkey Phone: +90 4423906857 E-mail: pinar.tosun@gmail.com ORCID: orcid.org/0000-0002-7296-5536

Received: 04.07.2021 Accepted: 31.08.2021

Cite this article as: Tosun Taşar P, Karaşahin Ö, Ural Karaman E, Serin BN, Urvasızoğlu TB, Akgöl Gür ST, Sevinç C. Factors Associated with Mortality in Geriatric Patients Presenting to the Emergency Department After Falls. Eur J Geriatr Gerontol 2021;3(3):171-176

๑Copyright 2021 by the Academic Geriatrics Society / European Journal of Geriatrics and Gerontology published by Galenos Publishing House. 


\section{Materials and Methods}

Inclusion criteria: The study included patients over 65 years of age who presented to the emergency department of our university due to falls between January and December 2019.

Exclusion criteria: Patients who were under 65 years of age and presented to the emergency department for complaints other than falls were not included.

Data were collected retrospectively from the hospital information system and patient files. Demographic data (such as age and sex), chronic diseases, medications used, and date of admission to the emergency department were recorded. The patients' chronic diseases were determined from the hospital information system according to International Statistical Classification of Diseases and Related Health Problems codes.

Degree of fall-induced injury was assessed and recorded as none, minor (such as bruises and abrasions not requiring medical intervention), moderate (serious wounds requiring stitches), or severe (head trauma, fractures), and the location of any fractures was noted. Biomarkers such as hemoglobin $(\mathrm{g} / \mathrm{dL})$, white blood cells $(\mu \mathrm{L} / \mathrm{mL})$, lymphocytes $(\mathrm{mcl})$, platelets $\left(10^{9} / \mathrm{L}\right)$, mean platelet volume $(\mathrm{fL})$, alanine aminotransferase $(\mathrm{U} / \mathrm{L})$, aspartate aminotransferase (U/L), alkaline phosphatase (IU/L), gamma glutamyl transferase $(\mathrm{U} / \mathrm{L})$, total bilirubin $(\mathrm{mg} / \mathrm{dL})$, direct bilirubin $(\mathrm{mg} / \mathrm{dL})$, blood urea nitrogen (BUN) $(\mathrm{mg} / \mathrm{dL})$, creatinine $(\mathrm{mg} / \mathrm{dL})$, total protein $(\mathrm{g} / \mathrm{dL})$, albumin $(\mathrm{mg} / \mathrm{dL})$, biomarker values, sodium $(\mathrm{mEq} / \mathrm{L})$, potassium $(\mathrm{K})(\mathrm{mmol} / \mathrm{L})$, chlorine, calcium $(\mathrm{mg} /$ $\mathrm{dL})$, phosphorus $(\mathrm{mg} / \mathrm{dL})$, magnesium $(\mathrm{mg} / \mathrm{dL})$, and glucose $(\mathrm{mg} /$ $\mathrm{dL}$ ) measured upon admission to the emergency department were obtained from the hospital system. Post-fall survival information was obtained from the official death reporting system of the Republic of Turkey Ministry of Health, General Directorate of Public Health using the patients' citizenship numbers.

\section{Statistics}

The data were analyzed using a commercial statistical software package. Categorical data were presented as frequency distribution and percentage, continuous variables as mean \pm standard deviation or median (minimum-maximum values). For comparisons between groups, chi-square test was used for categorical data and the non-parametric Kruskal-Wallis and Mann-Whitney $U$ tests were used for continuous data due to the non-normal data distributions. Receiver operating characteristic analysis was used to assess the predictive power of the biomarkers by determining the sensitivity and specificity of the identified cut-off points. Youden index (J=sensitivity + specificity - 1) was used to determine optimal cut-off values. Factors significantly associated with survival time were identified using Kaplan-Meier analysis. These factors were then used to generate a Cox regression model (forward: LR, entry: 0.05 and removal: 0.10 ). P-values $<0.05$ were considered statistically significant.

The study was conducted after obtaining approval from the Atatürk University Ethics Committee (dated 17/12/2020, ethics committee number 554).

\section{Results}

The 170 patients included in the study had a median age of 78.0 (minimum-maximum: 65-99) years and 87 (51.2\%) were male. The median follow-up time was 441 (minimum-maximum: 9-651) days. The prevalence of recurrent falls was 6.5\% $(n=11)$ in the first month, $12.9 \%(n=12)$ within 6 months, and $20.0 \%$ $(n=34)$ within 1 year after a fall. We analyzed 60-day mortality after recurrent falls. It was also noted whether the patient was hospitalized after the fall, and if hospitalized, what ward they were admitted to and how they were discharged. Surviving patients lived for between 364 and 651 days after recurrent falls according to follow-up records. Comparisons of the patients' demographic characteristics, comorbidities, and biomarker values between cases with and without mortality within 60 days post fall are presented in Table 1.

Hemoglobin, total protein, and albumin levels were significantly lower and age, BUN, and creatinine values were significantly higher among patients who died within 60 days after the fall when compared with survivors. The post-fall mortality rate was significantly higher among patients with chronic heart failure and patients who had fall-induced fractures or severe injury $(p<0.05)$. In terms of fracture location, hip/femur fractures were the most common and associated with significantly more deaths $(p<0.05)$.

For biomarkers that differed statistically between cases with and without 60-day post-fall mortality, their predictive power, sensitivity, and specificity according to the determined cut-off values are presented in Table 2. With a cut-off value of $11.55 \mathrm{~g} /$ $\mathrm{dL}$, hemoglobin had the highest predictive power for post-fall mortality.

Some of the variables that were significantly associated with survival time are presented in Table 3. A Cox regression model was created to determine the risk factors associated with average survival time after a fall. The last row is presented in Table 4.

\section{Discussion}

Falls occur frequently in the older population and lead to reduced functional capacity, hospitalization, and increased health expenditures. In the present study, in oldest-old adults had higher mortality after falls, consistent with the literature (13). This finding may be explained by higher rates of chronic diseases that increase with age, such as osteoporosis, dementia, 


\begin{tabular}{|c|c|c|c|}
\hline & \multicolumn{2}{|c|}{ 60-day post-fall mortality } & \multirow[b]{2}{*}{$p$} \\
\hline & Yes $(n=11)$ & No $(n=159)$ & \\
\hline Age $^{* *}$ & 85 (73-95) & 77 (65-99) & 0.003 \\
\hline \multicolumn{4}{|l|}{ Sex } \\
\hline Male & $6(54.5 \%)$ & $81(50.9 \%)$ & 0.817 \\
\hline Female & $5(45.5 \%)$ & $78(49.1 \%)$ & - \\
\hline \multicolumn{4}{|l|}{ Comorbidities } \\
\hline Hypertension & $7(63.6 \%)$ & $102(64.2 \%)$ & 0.973 \\
\hline Diabetes mellitus & $2(18.2 \%)$ & $48(30.2 \%)$ & 0.398 \\
\hline Coronary artery disease & $5(45.5 \%)$ & $41(25.8 \%)$ & 0.156 \\
\hline Chronic heart failure & $3(27.3 \%)$ & $8(5.0 \%)$ & 0.025 \\
\hline Depression & $2(18.2 \%)$ & $23(14.5 \%)$ & 0.736 \\
\hline Chronic kidney disease & $2(18.2 \%)$ & $7(4.4 \%)$ & 0.107 \\
\hline COPD & $1(9.1 \%)$ & $28(17.6 \%)$ & 0.409 \\
\hline Cerebrovascular event & $3(27.3 \%)$ & $15(9.4 \%)$ & 0.096 \\
\hline Parkinson's disease & $1(9.1 \%)$ & $7(4.4 \%)$ & 0.478 \\
\hline Alzheimer's disease & - & $29(18.2 \%)$ & 0.120 \\
\hline Malignancy & $1(9.1 \%)$ & $8(5.0 \%)$ & 0.561 \\
\hline Hyperthyroidism & - & $4(2.5 \%)$ & 0.594 \\
\hline Hypothyroidism & $1(9.1 \%)$ & $8(5.0 \%)$ & 0.561 \\
\hline Number of diseases** & $3(0-6)$ & $3(0-7)$ & 0.216 \\
\hline Number of medications used ${ }^{* *}$ & $5(0-9)$ & $4(0-10)$ & 0.245 \\
\hline Polypharmacy & $6(54.5 \%)$ & $62(39.0 \%)$ & 0.309 \\
\hline Use of antipsychotics & $1(9.1 \%)$ & $19(11.9 \%)$ & 0.776 \\
\hline \multicolumn{4}{|l|}{ Fall-induced injury } \\
\hline Physical damage & $8(72.7 \%)$ & $74(46.5 \%)$ & 0.093 \\
\hline Minor & - & $19(11.9 \%)$ & 0.224 \\
\hline Moderately & $2(18.2 \%)$ & $12(7.5 \%)$ & 0.215 \\
\hline Severe physical damage & $6(54.5 \%)$ & $42(26.4 \%)$ & 0.045 \\
\hline Fracture & $6(54.5 \%)$ & $37(23.3 \%)$ & 0.021 \\
\hline Femur/hip & $5(83.3 \%)$ & $9(24.3 \%)$ & 0.010 \\
\hline Costa & $1(16.7 \%)$ & $9(24.3 \%)$ & 0.680 \\
\hline Humerus & - & $4(10.8 \%)$ & 0.398 \\
\hline Vertebra & - & $6(16.2 \%)$ & 0.288 \\
\hline Radius & - & $4(10.8 \%)$ & 0.398 \\
\hline Orbita/maxilla/frontal & - & $5(13.5 \%)$ & 0.338 \\
\hline \multicolumn{4}{|l|}{ Laboratory results** } \\
\hline Hemoglobin (g/dL) & $10.6(8.9-14)$ & $13.30(8.5-18.8)$ & 0.001 \\
\hline WBC count $(\mu \mathrm{L} / \mathrm{mL})$ & $\begin{array}{l}8600 \\
(3040-14860)\end{array}$ & $\begin{array}{l}8490 \\
(1870-16410) \\
\end{array}$ & 0.778 \\
\hline Lymphocyte count (mcl) & $\begin{array}{l}1290 \\
(300-2470)\end{array}$ & $\begin{array}{l}1520 \\
(260-4230)\end{array}$ & 0.214 \\
\hline Platelet count $\left(10^{9} / \mathrm{L}\right)$ & $\begin{array}{l}228000 \\
(91000-386000)\end{array}$ & $\begin{array}{l}236000 \\
(48000-789000)\end{array}$ & 0.262 \\
\hline Glucose (mg/dL) & 128 (94-238) & $120(69-443)$ & 0.504 \\
\hline BUN (mg/dL) & $35(21-75)$ & $20.5(2.1-76.6)$ & $<0.001$ \\
\hline Creatinine $(\mathrm{mg} / \mathrm{dL})$ & $1.30(0.70-2.84)$ & $0.89(0.40-5.00)$ & 0.006 \\
\hline
\end{tabular}




\begin{tabular}{|l|l|l|l|}
\hline Table 1. Continued & \multicolumn{2}{l|}{ 60-day post-fall mortality } & \\
\hline & Yes (n=11) & No $(\mathbf{n}=\mathbf{1 5 9})$ & $\mathbf{p}$ \\
\hline Sodium $(\mathrm{mEq} / \mathrm{L})$ & $137(131-141)$ & $139(125-147)$ & 0.059 \\
\hline Potassium $(\mathrm{mmol} / \mathrm{L})$ & $4.37(3.30-6.40)$ & $4.00(2.62-6.01)$ & 0.070 \\
\hline Chloride $(\mathrm{mEq} / \mathrm{L})$ & $103(93-110)$ & $103(102-116)$ & 0.620 \\
\hline Calcium $(\mathrm{mg} / \mathrm{dL})$ & $8.7(8.2-10.4)$ & $9.1(4.5-10.5)$ & 0.112 \\
\hline Phosphorus $(\mathrm{mg} / \mathrm{dL})$ & $3.3(2.5-4.9)$ & $3(1.2-13.9)$ & 0.072 \\
\hline Magnesium $(\mathrm{mg} / \mathrm{dL})$ & $1.97(1.18-2.20)$ & $1.90(1.20-3.00)$ & 0.562 \\
\hline Total protein (g/dL) & $6.7(6.3-7.8)$ & $7.2(4.4-8.3)$ & $\mathbf{0 . 0 1 3}$ \\
\hline Albumin $(\mathrm{mg} / \mathrm{dL})$ & $3.4(3-3.8)$ & $3.8(2.4-4.65)$ & $\mathbf{0 . 0 0 1}$ \\
\hline${ }^{*}$ Mann-Whitney U or chi-square test. ${ }^{* *}$ Median (minimum-maximum) & & \\
\hline
\end{tabular}

Table 2. The predictive power, sensitivity, and specificity of biomarkers for post-fall mortality determined by ROC analysis with Youden index to determine cut-off point

\begin{tabular}{|l|l|l|l|l|l|}
\hline Variable & Cut-off point & AUC (95\% Cl) & Sensitivity (\%) & Specificity (\%) & p \\
\hline Hemoglobin $(\mathrm{g} / \mathrm{dL})$ & $11.55 \mathrm{~g} / \mathrm{dL}$ & $82.8(69.6-96.1)$ & 82.4 & 72.7 & $\mathbf{0 . 0 0 1}$ \\
\hline BUN $(\mathrm{mg} / \mathrm{dL})$ & 26.55 & $81.6(71.7-91.5)$ & 81.8 & 72.4 & $<0.001$ \\
\hline Creatinine $(\mathrm{mg} / \mathrm{dL})$ & 0.93 & $74.8(61.3-88.2)$ & 81.8 & 59.6 & $\mathbf{0 . 0 0 6}$ \\
\hline Total protein $(\mathrm{g} / \mathrm{dL})$ & 6.95 & $73.3(58.2-88.5)$ & 67.6 & 80.0 & $\mathbf{0 . 0 1 4}$ \\
\hline Albumin $(\mathrm{mg} / \mathrm{dL})$ & 3.53 & $80.3(70.6-90.0)$ & 80.0 & $\mathbf{0 . 0 0 1}$ \\
\hline AUC: Area under the curve, BUN: Blood urea nitrogen, Cl: Confidence interval, ROC: Receiver operating characteristic & \\
\hline
\end{tabular}

Table 3. Relationship between selected variables and post-fall survival time (Kaplan-Meier analysis)

\begin{tabular}{|l|l|l|}
\hline & $\begin{array}{l}\text { Mean survival days } \\
\mathbf{( 9 5 \%} \text { Cl) }\end{array}$ & $\mathbf{p}$ \\
\hline Age $>84$ years & $543.4(471.5-615.3)$ & $\mathbf{0 . 0 0 1}$ \\
\hline Chronic heart disease & $480.9(320.4-641.3)$ & $\mathbf{0 . 0 0 3}$ \\
\hline Hemoglobin $<11.55 \mathrm{~g} / \mathrm{dL}$ & $510.3(424.9-595.7)$ & $<\mathbf{0 . 0 0 1}$ \\
\hline BUN $>26.55 \mathrm{mg} / \mathrm{dL}$ & $542.6(478.7-606.4)$ & $<\mathbf{0 . 0 0 1}$ \\
\hline Creatinine $>0.93 \mathrm{mg} / \mathrm{dL}$ & $572.4(525.0-619.8)$ & $\mathbf{0 . 0 0 8}$ \\
\hline Total protein $<6.95 \mathrm{~g} / \mathrm{dL}$ & $561.0(504.0-618.1)$ & $\mathbf{0 . 0 0 2}$ \\
\hline Albumin $<3.53 \mathrm{mg} / \mathrm{dL}$ & $527.6(451.6-603.7)$ & $<\mathbf{0 . 0 0 1}$ \\
\hline Fracture & $539.5(477.5-601.5)$ & $\mathbf{0 . 0 1 9}$ \\
\hline Severe physical damage & $571.8(513.3-630.3)$ & $\mathbf{0 . 0 4 2}$ \\
\hline BUN: Blood urea nitrogen, Cl: Confidence interval & \\
\hline
\end{tabular}

Table 4. Cox regression model for risk factors associated with survival

\begin{tabular}{|l|l|l|l|l|}
\hline & Beta & $\begin{array}{l}\text { Hazard } \\
\text { ratio }\end{array}$ & $\mathbf{9 5 \%} \mathbf{C l}$ & $\mathbf{p}$ \\
\hline Creatinine $>0.93 \mathrm{mg} / \mathrm{dL}$ & 1.503 & 4.494 & $0.951-21.245$ & 0.058 \\
\hline Hemoglobin $<11.55 \mathrm{~g} / \mathrm{dL}$ & 1.703 & 5.488 & $1.078-27.931$ & $\mathbf{0 . 0 4 0}$ \\
\hline Albumin $<3.53 \mathrm{mg} / \mathrm{dL}$ & 2.088 & 8.066 & $1.585-41.062$ & $\mathbf{0 . 0 1 2}$ \\
\hline Cl: Confidence interval
\end{tabular}

and Parkinson's disease, as well as the presence of geriatric syndromes such as polypharmacy, malnutrition, dementia, reduced mobility, and greater functional dependence. In addition, we observed that the mortality rate was higher among patients who had fall-induced fracture or severe injury, which is expected.

Studies of older people with hip fractures have shown that those with low hemoglobin and albumin levels have higher mortality rates at 1 month and 1 year $(14,15)$. In the present study, hemoglobin level $<11.55 \mathrm{~g} / \mathrm{dL}$ was found to increase the risk of mortality within the first 2 months by 5.488 times. Anemia in older adults can be caused by blood loss, malignancy, decreased iron intake or absorption, chronic inflammation, endocrine and metabolic causes, increased rate of red blood cell destruction, reduced dietary intake, and drug-related side effects (16). Although the causes of anemia were not elucidated in our study, there are similar reports in the literature associating anemia with higher mortality after falls.

Malnutrition is among the risk factors for falls. Studies in the United States and Australia have shown that 12\% to 16\% of older adults presenting to emergency departments are malnourished $(17,18)$. Although malnutrition screening was not performed in our study, the results demonstrated that albumin level $<3.53$ $\mathrm{mg} / \mathrm{dL}$ in older adults with falls increased the risk of mortality by 8.066 times. In the literature, there are studies showing a relationship between serum albumin level and mortality in 
studies conducted among the elderly (19). For example, among older adults hip fractures, rates of postoperative complications such as sepsis and mortality were higher in those with albumin levels below $3.5 \mathrm{mg} / \mathrm{dL}$ (20). Studies conducted among patients undergoing elective surgery for various reasons have also shown that albumin level is the strongest predictor of mortality $(21,22)$. In patients with sarcopenia and in inflammatory conditions, cytokines such as IL-6 and TNF- $\alpha$ are among the causes of low albumin level (23). However, it was also not determined in these studies whether hypoalbuminemia was due to malnutrition, disease progression, nephrotic syndrome, chronic liver injury, or systemic inflammation. As in these studies, our results showed that the presence of hypoalbuminemia was associated with higher mortality after falls, but the causes of this hypoalbuminemia were not investigated.

Although we did not evaluate glomerular filtration rate or whether the patients received renal replacement therapy, patients with renal dysfunction showed a higher mortality rate in the first 2 months post fall. This is also consistent with the literature $(24,25)$. Falls are an important cause of morbidity and mortality among individuals with chronic kidney disease. These patients are at increased risk of falls due to the presence of muscle, hematologic, endocrine, and metabolic disorders, comorbidities, vitamin D deficiency (26), orthostatic hypotension after hemodialysis, diabetic neuropathy, sarcopenia $(27,28)$, and polypharmacy $(29,30)$.

Studies of older patients with hip fractures have also shown that the presence of pulmonary disease, dementia, chronic lung disease, and malignancy increased mortality $(15,31)$. In the present study, heart failure was associated with higher mortality. This may be because heart failure patients usually use antihypertensive drugs that can cause orthostatic hypotension as a side effect, and the use of anticoagulant and antiaggregant drugs increases the risk of bleeding and severe fall-related injury.

\section{Study Limitations}

This study has certain limitations. Firstly, it was conducted retrospectively, in a single center, and with a relatively small patient sample. Geriatric syndromes such as malnutrition, decubitus ulcers, delirium, depression, and dementia that may be associated with post-fall mortality were not investigated. Furthermore, the study did not take into account other prognostic indicators that could have been used, such as the patients' vital signs or the Charlson comorbidity index.

The aging global population makes the issue of falls in older adults increasingly important. As the first analysis of factors associated with mortality in geriatric patients presenting to the emergency department after falls, we believe that this study will make a valuable contribution to the literature and guide future studies on this subject.

\section{Conclusion}

Among older adults who presented to the emergency department after falls, mortality was higher among those with anemia and hypoalbuminemia at the time of admission, and these two conditions were found to be independent risk factors for mortality. Priority triage is recommended for these patients.

\section{Ethics}

Ethics Committee Approval: The study was conducted after obtaining approval from the Atatürk University Ethics Committee (dated 17/12/2020, ethics committee number 554).

Informed Consent: Retrospective study.

Peer-review: Externally peer-reviewed.

\section{Authorship Contributions}

Surgical and Medical Practices: P.T.T., Concept: P.T.T., T.B.U., C.S., Design: P.T.T., E.U.K., C.S., Data Collection or Processing: Ö.K., E.U.K., B.N.S., S.T.A.G., Analysis or Interpretation: P.T.T., Ö.K., S.T.A.G., Writing: P.T.T., Ö.K., C.S.

Conflict of Interest: No conflict of interest was declared by the authors.

Financial Disclosure: The authors declared that this study received no financial support.

\section{References}

1. Ang $\mathrm{GC}$, Low $\mathrm{SL}$, How $\mathrm{CH}$. Approach to falls among the elderly in the community. Singapore Med J 2020;61:116-121.

2. Alamgir $\mathrm{H}$, Muazzam $\mathrm{S}$, Nasrullah M. Unintentional falls mortality among elderly in the United States: time for action. Injury 2012;43:2065-2071.

3. Ensrud KE, Ewing SK, Cawthon PM, Fink HA, Taylor BC, Cauley JA, Dam $\Pi$, Marshall LM, Orwoll ES, Cummings SR; Osteoporotic Fractures in Men Research Group. A comparison of frailty indexes for the prediction of falls, disability, fractures, and mortality in older men. J Am Geriatr Soc 2009;57:492-498.

4. Panel on Prevention of Falls in Older Persons, American Geriatrics Society and British Geriatrics Society. Summary of the Updated American Geriatrics Society/British Geriatrics Society clinical practice guideline for prevention of falls in older persons. J Am Geriatr Soc 2011;59:148-157.

5. Orces $\mathrm{CH}$. Emergency department visits for fall-related fractures among older adults in the USA: a retrospective cross-sectional analysis of the National Electronic Injury Surveillance System All Injury Program, 20012008. BMJ Open 2013;3:e001722.

6. Albert M, McCaig LF, Ashman JJ. Emergency department visits by persons aged 65 and over: United States, 2009-2010. NCHS Data Brief 2013;1-8.

7. Miró Ò, Nayla Brizzi B, Aguiló S, Alemany X, Jacob J, Llorens P, Herrero Puente $P$, González Ramón B, Castro Jiménez V, Torres Machado V, Cenjor R, Gil A, Rico V, Martínez Nadal G, Lázaro Del Nogal M, Martín-Sánchez FJ. Profile of older patients attended in the emergency department after falls: a FALL-ER registry study of the magnitude of the problem and opportunities for improving hospital emergency care. Emergencias 2018;30:231-240.

8. Carpenter CR, Avidan MS, Wildes T, Stark S, Fowler SA, Lo AX. Predicting geriatric falls following an episode of emergency department care: a systematic review. Acad Emerg Med 2014;21:1069-1082. 
9. Lin $\mathrm{CH}$, Liao KC, Pu SJ, Chen YC, Liu MS. Associated factors for falls among the community-dwelling older people assessed by annual geriatric health examinations. PLoS One 2011;6:e18976.

10. Thaler-Kall K, Döring A, Peters A, Thorand B, Grill E, Koenig W, Horsch A, Meisinger C. Association between anemia and falls in community-dwelling older people: cross-sectional results from the KORA-Age study. BMC Geriatr 2014;14:29.

11. Penninx BW, Pluijm SM, Lips P, Woodman R, Miedema K, Guralnik JM, Deeg DJ. Late-life anemia is associated with increased risk of recurrent falls. J Am Geriatr Soc 2005;53:2106-2111.

12. Tachi T, Yokoi T, Goto C, Umeda M, Noguchi Y, Yasuda M, Minamitani M, Mizui T, Tsuchiya T, Teramachi H. Hyponatremia and hypokalemia as risk factors for falls. Eur J Clin Nutr 2015;69:205-210.

13. Hagiya H, Koyama T, Zamami Y, Tatebe $Y$, Funahashi T, Shinomiya K, Kitamura $Y$, Hinotsu $S$, Sendo T, Rakugi $H$, Kano MR. Fall-related mortality trends in older Japanese adults aged $\geq 65$ years: a nationwide observational study. BMJ Open 2019;9:e033462.

14. Traven SA, Reeves RA, Althoff AD, Slone HS, Walton ZJ. New Five-Factor Modified Frailty Index Predicts Morbidity and Mortality in Geriatric Hip Fractures. J Orthop Trauma 2019;33:319-323.

15. Karres J, Kieviet N, Eerenberg JP, Vrouenraets BC. Predicting Early Mortality After Hip Fracture Surgery: The Hip Fracture Estimator of Mortality Amsterdam. J Orthop Trauma 2018;32:27-33.

16. Stauder $R$, Valent $P_{1}$, Theurl I. Anemia at older age: etiologies, clinical implications, and management. Blood 2018;131:505-514.

17. Vivanti $A$, Isenring E, Baumann S, Powrie D, O'Neill M, Clark D, Courtice $\mathrm{S}$, Campbell K, Ferguson M. Emergency department malnutrition screening and support model improves outcomes in a pilot randomised controlled trial. Emerg Med J 2015;32:180-183.

18. Marshall S, Young A, Isenring E. The Malnutrition Screening Tool in Geriatric Rehabilitation: A Comparison of Validity When Completed by Health Professionals With and Without Malnutrition Screening Training Has Implications for Practice. J Acad Nutr Diet 2018;118:118-124.

19. Corti MC, Guralnik JM, Salive ME, Sorkin JD. Serum albumin level and physical disability as predictors of mortality in older persons. JAMA 1994;272:1036-1042.
20. Symeonidis PD, Clark D. Assessment of malnutrition in hip fracture patients: effects on surgical delay, hospital stay and mortality. Acta Orthop Belg 2006;72:420-427.

21. Kudsk KA, Tolley EA, DeWitt RC, Janu PG, Blackwell AP, Yeary S, King BK. Preoperative albumin and surgical site identify surgical risk for major postoperative complications. JPEN J Parenter Enteral Nutr 2003;27:1-9.

22. Gibbs J, Cull W, Henderson W, Daley J, Hur K, Khuri SF. Preoperative serum albumin level as a predictor of operative mortality and morbidity: results from the National VA Surgical Risk Study. Arch Surg 1999;134:36-42.

23. Cabrerizo S, Cuadras D, Gomez-Busto F, Artaza-Artabe I, Marin-Ciancas F, Malafarina V. Serum albumin and health in older people: Review and meta analysis. Maturitas 2015;81:17-27.

24. Khan MA, Hossain FS, Ahmed I, Muthukumar N, Mohsen A. Predictors of early mortality after hip fracture surgery. Int Orthop 2013;37:2119-2124.

25. Lo LWT, Yanling X, Chou ACC, Howe TS, Allen JC, Koh JSB. End-Stage Renal Failure Is an Independent Risk Factor for 1-Year Mortality After Hip Fracture Surgery. Geriatr Orthop Surg Rehabil 2018;9:2151459318770561.

26. Papakonstantinopoulou K, Sofianos I. Risk of falls in chronic kidney disease J Frailty Sarcopenia Falls 2017;2:33-38.

27. Beaudart $C$, Zaaria M, Pasleau $F$, Reginster JY, Bruyère 0 . Health Outcomes of Sarcopenia: A Systematic Review and Meta-Analysis. PLoS One 2017;12:e0169548.

28. Moorthi RN, Avin KG. Clinical relevance of sarcopenia in chronic kidney disease. Curr Opin Nephrol Hypertens 2017;26:219-228.

29. Hammond T, Wilson A. Polypharmacy and falls in the elderly: a literature review. Nurs Midwifery Stud 2013;2:171-175.

30. Angalakuditi MV, Gomes J, Coley KC. Impact of drug use and comorbidities on in-hospital falls in patients with chronic kidney disease. Ann Pharmacother 2007;41:1638-1643.

31. Nijmeijer WS, Folbert EC, Vermeer M, Slaets JP, Hegeman JH. Prediction of early mortality following hip fracture surgery in frail elderly: The Almelo Hip Fracture Score (AHFS). Injury 2016;47:2138-2143. 